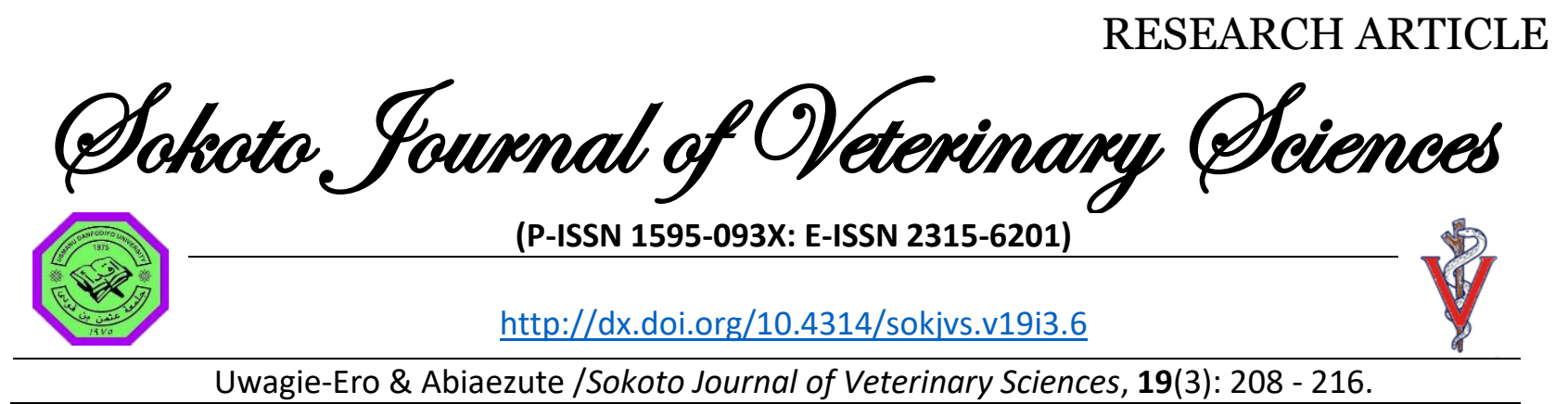

\title{
A retrospective study of avascular necrosis of the femoral head in dogs in Delta State, Nigeria
}

\author{
EA Uwagie-Ero ${ }^{1 *} \&$ CN Abiaezute ${ }^{2}$ \\ 1 \\ Department of Veterinary Surgery, Faculty of Veterinary Medicine, University of Benin, Benin City, Edo \\ State, Nigeria \\ 2. \\ Department of Veterinary Anatomy, Faculty of Veterinary Medicine, University of Nigeria, Nsukka, Nigeria
}

*Correspondence: Tel.: +2348033977590; E-mail: edwin.uwagie-ero@uniben.edu

\begin{abstract}
Copyright: (c) 2021
Uwagie-Ero \&

Abiaezute This is an

open-access article

published under the

terms of the Creative

Commons Attribution

License which permits

unrestricted use,

distribution, and

reproduction in any

medium, provided the

original author and

source are credited.
\end{abstract}

Publication History:

Received: 23-03-2021

Revised: 03-06-2021

Accepted: 09-06-2021

\begin{abstract}
The study evaluated the prevalence of avascular necrosis of the femoral head in dogs in Delta State, Nigeria. For ten years, data of cases presented to Veterinary Clinics in five government clinics in Delta state were evaluated and analysed. The breed of dog, sex, age on presentation, the limb affected and the radiographic appearance of the lesions on presentation were reviewed. The treatment and clinical management approaches were also reviewed and discussed. Of the cases of avascular necrosis of the femoral head recorded $(\mathrm{N}=24)$ for the period under review, breed prevalence recorded $62.5 \%$ (Alsatians); $16.67 \%$ (Caucasians) and 20.83\% (Mixed Breeds). Sex prevalence recorded $79.17 \%$ females and $20.83 \%$ males. According to age at the time of the first presentation, $83.83 \%$ of the affected dogs were $6-12$ month old, $12.5 \%$ were $13-24$ month old, and $4.16 \%$ were 25-36 month-old. Lameness was observed in $91.67 \%$, while $8.33 \%$ of cases presented non-weight bearing lameness. Pain in the limbs during palpation of the hip joint was detected in $100 \%$ of the cases. Atrophy in the hind limb was identified in $41.66 \%$ of the patients, while $62.5 \%$ of the dogs showed different degrees of medial patellar luxation. In $91.6 \%$ of cases, the disease was unilateral, with $63.63 \%$ unilateral lesions in the right hind limb and $36.37 \%$ in the left hind limb. The study results showed a high prevalence of avascular necrosis of the femoral head in large breeds of dogs in the Delta state. The management of the disease is mainly conservative with poor follow-up. Cost of surgery and management may discourage owners from follow up. However, surgery remains the gold stand of care for managing avascular necrosis of the femoral head in dogs.
\end{abstract}

Keywords: Coxofemoral joint, Dogs, Legg-Calvé-Perthes disease, Osteonecrosis, Radiography

\section{Introduction}

Osteonecrosis of the femoral head, often referred to clinically as avascular necrosis of the femoral head, is a pathological condition of the femoral head that causes a decrease in blood supply to the subchondral bone of the femoral head, which results in osteocyte death and collapse of the articular surface of the bone (Jones, 1985; DeCamp et al., 2016). This condition and other pathologies such as Salter-Harris fractures 
(fractures of the femoral head and neck in growing animals), acetabular fractures, coxofemoral joint luxation and hip dysplasia may compromise the integrity of the coxofemoral joint and result in lameness. The condition, often referred to as LeggCalvé-Perthes disease (Jones, 1985; DeCamp et al., 2016) is a developmental disease caused by ischemic necrosis, which is commonly seen in young dogs (Jones, 1985; Gambrardella, 1993; Demko \& McLaughin, 2005; Cardoso, 2018). Several aetiology such as trauma, infection (Demko \& McLaughin, 2005), hereditary (Gambardella, 1993), hormonal imbalance (Robinson, 1992), vascular abnormalities (Ginja et al., 2010), metabolic imbalances (Towle \& Beuer, 2012) and developmental anatomic deformities (Kim, 2011) have been reported. Findings reveal that there is a relationship between the onset of the disease with age and clinical presentation (Gambardella, 1993). Clinically, the disease presents a palpable pain in the hip, pain on abduction, extension or minimal movement of the affected hind limb. Crepitation and a limitation in the degree of extension have also been reported (Nebzydoski, 1982; Jones, 1985; Gambardella, 1993; DeCamp et al., 2016). Typical clinical presentation is a shortening of the hind limb with a prominence of the greater trochanter and atrophy of the gluteal and quadriceps muscles (Nebzydoski, 1982: Jones, 1985; Gambardella, 1993; Demko \& McLaughin, 2005; Madore et al., 2007). Severe cases may compromise hind limb usage, locomotion and subsequent no weight bearing at all on the hind limb (Nebzydoski, 1982; Jones, 1985). The diagnosis is based on imaging such as radiography and magnetic resonance imaging (Nebzydoski, 1982; Jones, 1985; Bowlus et al., 2008). Radiographic findings may reveal enlargement at early stages and a flattening or collapse of the femoral head at late stages. Hip dysplasia is often considered for the differential diagnosis in dogs (Ginja et al., 2010; Kobayashi et al., 2015). However, hip dysplasia may present a history of chronic onset with occasional micro-fracture, but there is no significant range of sub-chondral bone necrosis and degeneration (Ginja et al., 2010; Kobayashi et al., 2015).

This study reviewed the prevalence of avascular necrosis of the femoral head in dogs presented to veterinary clinics in Delta State to review the basic clinicopathological features presented by the disease and analyse the radiographic findings.

\section{Materials and Methods}

Data collection
Clinical and radiographic records of dogs presented, diagnosed and treated for avascular necrosis of the femoral head during the period from January 2009 to January 2019 in state government-owned clinics located in Warri, Sapele, Effurun, Agbor and Ughelli in Delta State were analysed. This was to determine the prevalence of the disease and radiographic findings reported. The breed of dog, sex, age on presentation, the affected limb and the significant radiographic features of the lesions seen on presentation were reviewed. The treatment and clinical management approaches were also reviewed. Breed of dog, age on presentation and sex prevalence were calculated and recorded. The affected limb, the radiographic evidence of necrosis of the femoral head, the history and clinical signs on presentation, the age and time of occurrence and the type of treatment and clinical management protocol applied were also evaluated. The lesions of the disease observed were subsequently classified based on the radiological appearance and stage of development of the lesions seen and graded from 1 to 5 as described in Table 1 (Kobayashi et al., 2015; Cardoso et al., 2016).

Radiographic changes seen in the clinical radiographs (Figure 1-6) were also recorded according to the lesion grades presented.

\section{Statistical analysis}

Data were analysed using Graph Pad Prism Version 7 for Windows. The simple linear regression analysis was used to quantify the relationship among lesion grades. The Spearman's correlation was subsequently used to analyse the association between lesion grade and other variables (gender, breed, and affected hind limb, unilateral or bilateral lesion). The differences were considered significant at $\mathrm{P}<0.05$. In addition, the data were analysed using descriptive statistics to feature the frequency of numerical variables.

\section{Results}

Twenty-four cases of avascular necrosis of the femoral head were identified in the present study. Breed prevalence showed $62.5 \%$ of the affected dogs were Alsatians ( $n=15) ; 16.67 \%$ were Caucasians ( $n=$ 4 ) and $20.83 \%$ were mixed breeds $(n=5)$ (Figure 7 ). Nineteen cases were females (79.17\%), and 5 were males (20.83\%) (Figure 8). According to the age group at the time of the first presentation, 20 dogs were within 6-12-month-old (83.83\%), three dogs were within 13-24-month-old (12.5\%), and one dog was 25-36-month-old (4.16\%) (Figure 9).

Lameness of the affected hind limb was observed in $91.67 \%(n=22)$ of the cases; $8.33 \%(n=2)$ of the lame dogs presented non-weight bearing lameness. 
Table 1: Grading of avascular necrosis of the femoral head in dogs

\begin{tabular}{ll}
\hline Lesion Grade & Clinical Presentations \\
\hline Grade 1 & $\begin{array}{l}\text { Acetabulum and contour of the femoral head and of the femoral neck are apparently normal, } \\
\text { and there is wide joint space, decreased density of the femoral head and of the femoral neck. } \\
\text { There is femoral head flattening and the presence of multiple density foci of decreased density, } \\
\text { the acetabular rim may contain a small spur. } \\
\text { There is irregularity in the articular surface of the femoral head and the presence of multiple } \\
\text { Grade } 3\end{array}$ \\
low-density foci, the spur is more prominent in the acetabular rim. \\
Grade 4 \\
$\begin{array}{ll}\text { There is loss of the normal shape of the femoral head, increased prevalence of areas with } \\
\text { decreased density. } \\
\text { There is fragmentation of the femoral head with discontinuity of the articular surface, and the } \\
\text { acetabular changes are more pronounced than those observed in Grade } 4 .\end{array}$
\end{tabular}

Figure l. Ventrodorsal radiographic views of the hip joints in dogs with avascular necrosis of femoral head a- Grade 1: Decreased density of the femoral head;

b- Grade 2: Flattering of the femoral head and presence of density foci of decreased density,

c- Grade 3: Iregularity of the articular surface of the femoral head and presence of multiple low density foci, spur on the acetabular rim;

Pain in the limbs on palpation of the hip joint was detected in $100 \%(N=24)$ of the cases. Atrophy in the hind limb was identified in $41.66 \%(n=10)$ of the affected dogs, and $62.5 \%$ ( $n=15$ ) of the dogs showed different degrees of medial patellar luxation. In 21 dogs (91.6\%), the disease was unilateral and in one dog, it was bilateral (4.16\%). Also $63.63 \%(n=14)$ of the unilateral lesions were

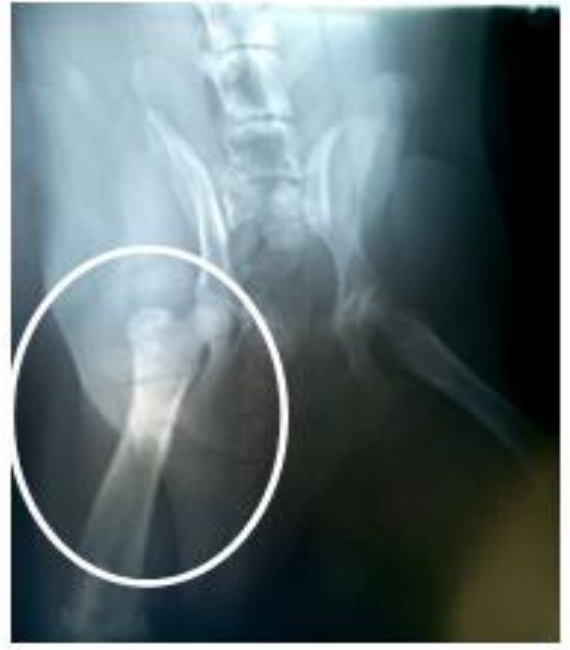

Figure 2: Radiograph of dog showing decreased bone density (Grade 1)

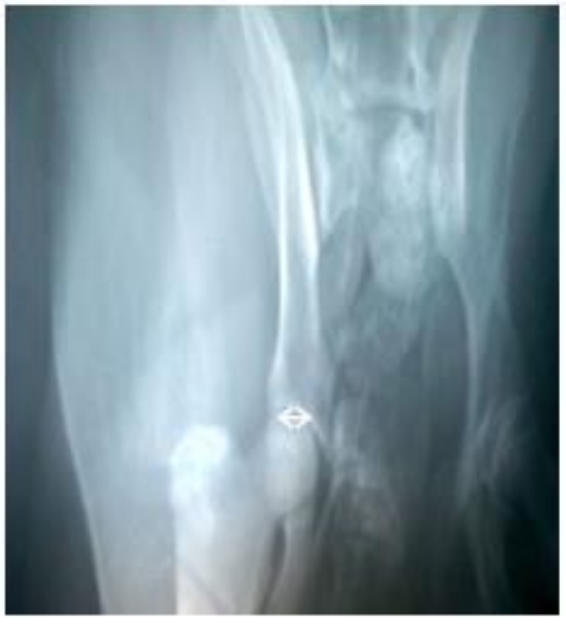

Figure 3: Radiograph of dog showing increased width of joint spaces (Grade 2) located in the right hind limb and $36.37 \%(n=8)$ in the left hind limb.

The radiographic grades of the lesion were not significant $(p>0.05)$ in the present study in comparison to other variables in both the simple linear regression and the Spearman's correlation. Thus, the descriptive analysis was done based on the radiographs: $18.83 \%$ were Grade $1(n=2) ; 16.67 \%$,
Grade $2(n=4) ; 16.67 \%$, Grade $3(n=4) ; 25 \%$, Grade $4(n=6)$; and $37.5 \%$, Grade $5(n=9)$ (Figure 10$)$. Surgical treatment was performed in 6 cases $(25 \%)$, and conservative treatment was done in 18 (75\%) cases. The owner did not return the dog for postoperative follow up in $50 \%(n=3)$ of the surgical cases $(n=6)$. 


\section{Discussions}

Young dogs have been reported to develop a debilitating hind limb condition, often resulting in lameness in which the femoral head degenerates and becomes necrotic due to ischemia. This condition, ischemic or avascular necrosis of the femoral head, also referred to clinically as Legg-Calvé-Perthes disease, generally appear between 3 and 13 months of life. The resulting lameness may be present for several weeks or may have a sudden onset (Gambardella, 1993). The present study reviewed 24 cases of dogs 6-36 months of age presented to be a result of avascular necrosis of the femoral head. Results showed that the syndrome was more prevalent in dogs between the ages of 13-24 month-old. At

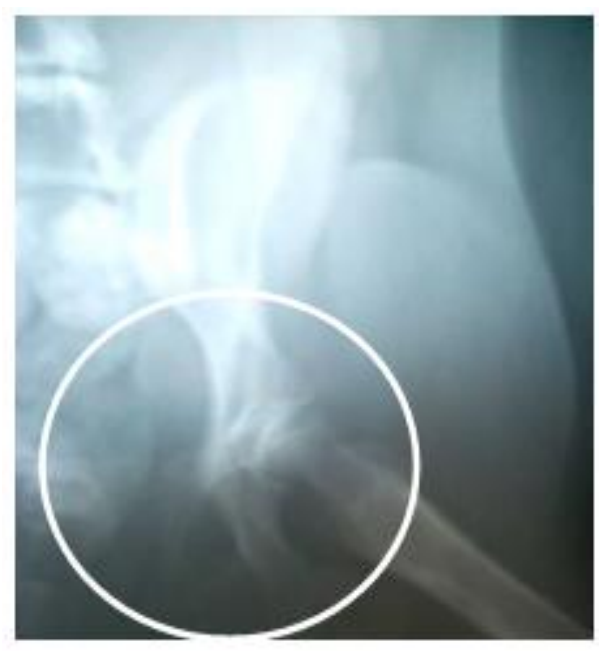

Figure 4: Radiograph of dog showing osteophyte Production (Grade 3)

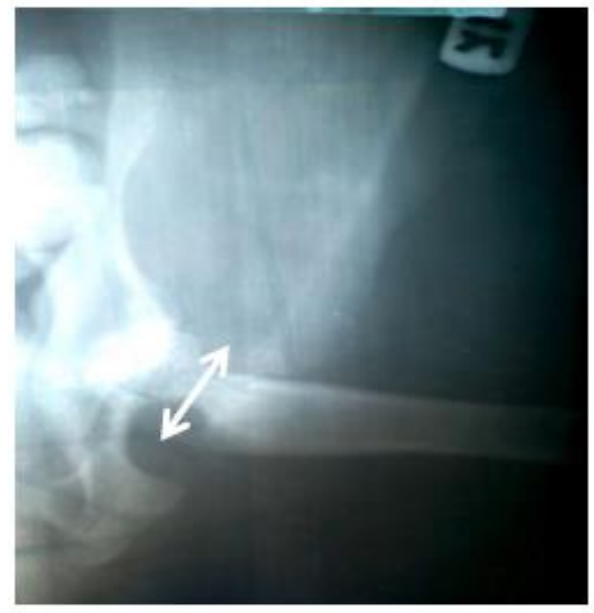

Figure 6: Radiograph of the dog showing femoral Head Fragmentation (Grade 5)

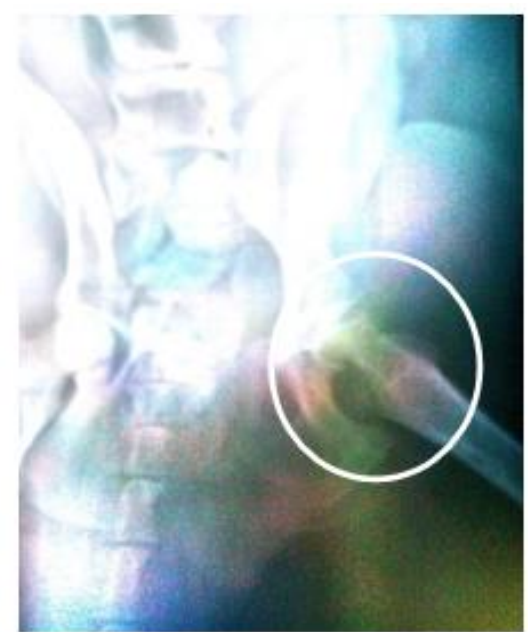

Figure 5: Radiograph of dog showing flattening of the articular Surfaces of the Femoral head (Grade 4)

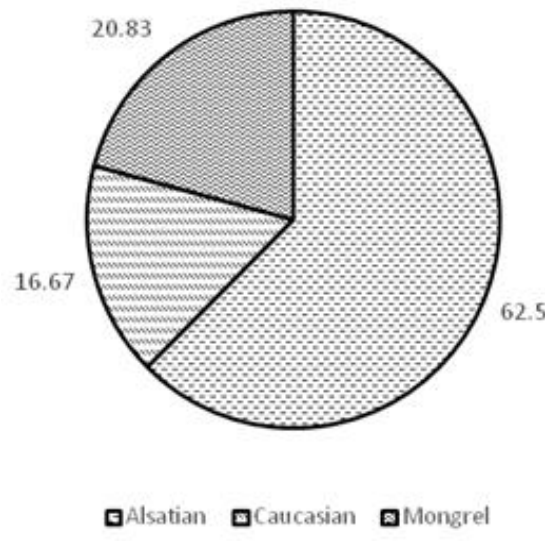

Figure 7: Breed distribution of lesions of Avascular Necrosis of the femoral head the time of clinical presentation, only one dog was 36month-old. This correlate report that the disease is more prevalent in young dogs (Lika et al., 2012). This may also be due to owners not presenting the dogs to the clinics at the onset of lameness or trying conservative management of observed lameness on their own before presentation to the clinics. More so, owners may not recognise the clinical signs early enough.

Twenty-four cases of avascular necrosis of the femoral head were diagnosed. Sixty-two and a half (62.5\%) of the different breeds of dogs recorded were Alsatians; $16.67 \%$ were Caucasians, and $20.83 \%$ were of mixed breeds.

More female dogs (79.17\%) were presented than males $(20.83 \%)$. In addition, the age at the time of the first presentation, younger (juvenile) dogs (83.83\%) between 6-12 months old were presented as compared to adolescent (13-24-month-old) dogs (12.5\%) and adults (25-36-month-old) dogs (4.16\%). Alsatian and Caucasian breeds observed to have a high prevalence in this study were large breeds of dogs; this is contrary to reports of the disease being more common in small breeds of dogs; however, this difference in breed predisposition can be due to the fact that the small breeds of dogs are not commonly kept by pet owners in the region under study as compared to the large breeds. Most dog owners in southern Nigeria keep dogs mostly for security purposes, and this may contribute to the low incidence of the disease in small breeds in the region (24 of 3215 cases presented to the clinics under review for a period of 10 years). Small breeds of dogs 


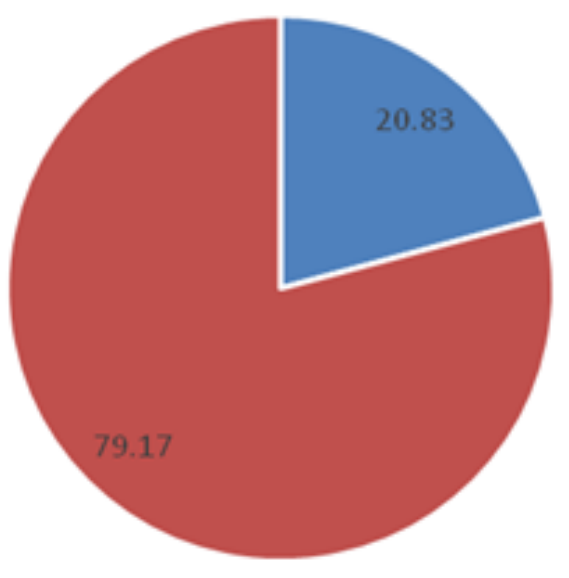

" Male = Female

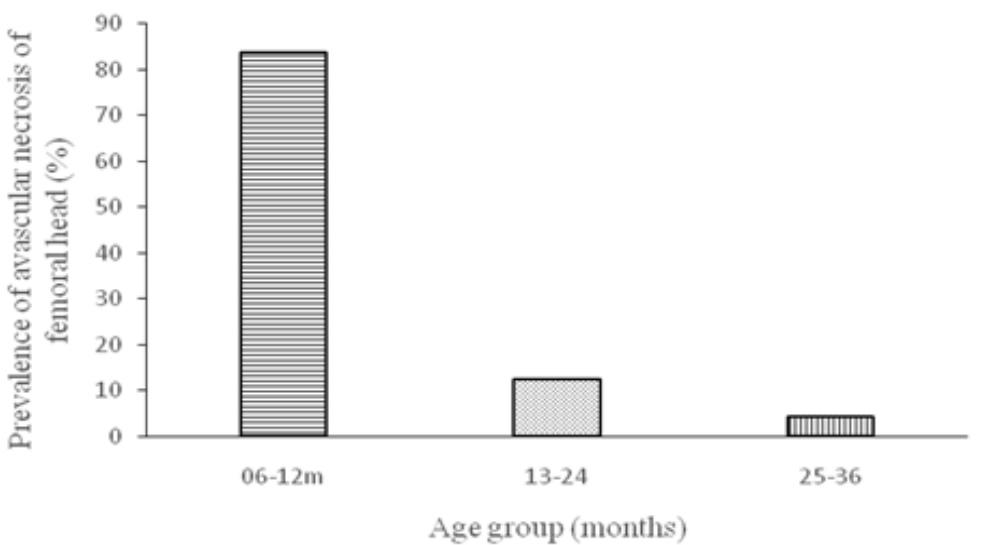

Figure 8: Prevalence of Avascular Necrosis of the femoral head based on sex

such as the West Highland White Terrier, Cairn terrier and poodle have been reported amongst the breeds commonly affected (Harper, 2017). In an earlier study comprising 35 dogs, $60 \%$ were Yorkshire terriers (Millis, 2014). In another study comprising 14 dogs, the incidence of the disease was higher in Pekingese and Terrier breeds (Lika et al., 2012). The differences observed in these studies may be associated with the different socio-economic and geographic regions and the breed preference of pet owners.

Studies have also reported a high prevalence of avascular necrosis of the femoral head in dogs, with an average mean body weight of

Figure 9: Age Distribution of Lesions

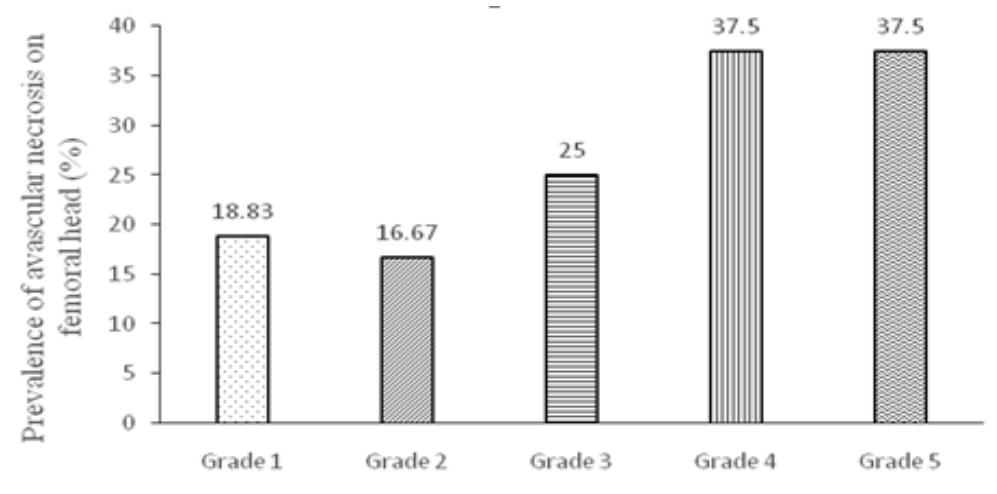

Distribution of lesions based on radiographic grades

Figure 10: Age Distribution of lesions according to Radiographic Grading of Avascular Necrosis of the Femoral Head

4-6 kg matches the small breeds of dogs (Demko \& McLaughin, 2005; Towle \& Beuer, 2012; Cardoso et al., 2018). This study, however, did not compare the mean bodyweight of the dogs with the disease prevalence.

About seventy-nine percent $(79.17 \%)$ of the total cases reviewed in this study were females, and $20.83 \%$ were males, supporting an earlier study that had also reported high sex prevalence for females (Lika et al., 2012) while another study of 188 cases (Cardoso et al., 2018) reported no sex prevalence for the disease.

Early clinical signs of non-weight-bearing lameness or an intermittent subtle lameness have been reported in avascular necrosis of the femoral head (Nebzydoski, 1982; Demko et al., 2005). Complete physical and radiographic examinations must be conducted to eliminate the possibility of slipped upper femoral epiphyses, fracture of the femoral

neck, hip dysplasia and patella luxation. Weightbearing lameness of the affected hind limb was observed in $91.67 \%$ of the cases in this study, while $8.33 \%$ of cases presented non-weight bearing lameness. Pain in the limbs during palpation of the hip joint was detected in $100 \%$ of the cases; this has also been previously reported, and in general, the pain may get worse during hip joint abduction (Nebzydoski, 1982). Atrophy in the hind limb muscle was identified in $41.66 \%$ of the dogs, and $62.5 \%$ of the dogs showed different degrees of medial patellar luxation. In this study, $6.97 \%$ of the cases reviewed were bilateral and thus agreed with an earlier report that bilateral avascular necrosis of the femoral head is rare. (Towle \& Beuer, 2012; Cardoso et al., 2018), Based on the clinical, radiographic appearance of the lesions, avascular necrosis of the femoral head has been classified into five grades (Madore et al., 2007; Cardoso et al., 2018). The common radiographic 
features includes: areas of decreased bone density close to the epiphyseal line in early cases; increased width of the joint space seen in the early course of the disease persists throughout the disease. An initial osteophyte production in the anterolateral aspect of the acetabulum becomes more pronounced as the condition persists. Also reported is the flattening of the articular surface of the femoral head ranging from the minimal loss of the articular contour of the anterodorsal aspect of the articular surface to a marked concave depression of the anterodorsal aspect to complete disruption with loss of contour of the articular surface and fragmentation of the femoral head (George, 1992; David et al., 2012; Cardoso et al., 2018)

The radiographic grade of the lesion was not significant in the present study; therefore, a descriptive analysis was done based on the radiographic classification: $18.83 \%$ were Grade 1, $16.67 \%$ Grade 2; $16.67 \%$ Grade 3; $25 \%$ Grade 4 and $37.5 \%$ Grade 5. Non-operative management and treatment of osteonecrosis involved the application of non-invasive methods to dissipate and reduce the force and load-bearing on the affected hip by the use of splints, bandages or a walker and cane, thus decreasing weight-bearing on the affected hind limb. Furthermore, a modification of the dogs' routine activities and, in some cases, exercise limitation and control, as well as physiotherapy, have been advocated (Cardoso et al., 2018). These methods, however, have not shown any significant impact in the treatment and management of osteonecrosis, especially at the late stages. More so, limited was recorded by the use of these methods in preventing disease progression even at the onset or very early stages of the disease (Cardoso et al., 2018). In this study, surgical treatment was performed in 6 cases (25\%), and conservative treatment was applied in 18 cases $(75 \%)$. However, the owners did not return the dogs for postoperative follow-up in up to $50 \%$ of the surgical cases. From the study, the stage 5 lesions of avascular necrosis of the femoral head were more frequent; the prognosis was poor to guarded. The high prevalence of Grade 5 lesions may be associated with chronic lameness resulting from late diagnosis and delay in the institution of care and management of the condition. Surgical management with intensive care is often required. In some cases, it has been reported that a second surgery may be needed to remove the remaining part of the femoral head in order to achieve total recovery (David et al., 2012; Cardoso et al., 2018) and functional recovery of the affected hind limb may also require physiotherapy and rehabilitation.
A study comprising seven dogs with unilateral avascular necrosis of the femoral head found that the radiographic areas presenting decreased density in Grades 2 and 3 did not alter the global mineral content of the scanned regions in dual-energy X-ray absorptiometry scans (Isola et al., 2005).

In assessing the treatment options and novel strategies in the management of avascular necrosis of the femoral head, it must be noted that vascular damage and resultant ischemia is a crucial factor in the pathogenesis of avascular osteonecrosis. Scientists have tried to experimentally simulate the injury by inducing vascular deprivation and ischemia clinically (Levin et al., 1999; Vadasz et al., 2004; Peled et al., 2009; Terayama et al., 2011). The usefulness of several novel therapies for osteonecrosis and the possible cellular and molecular mechanism that are involved in the pathology of the disease is being studied extensively using these models in the last few decades. The use of cellular therapies as a treatment option for osteonecrosis has also been considered. A recent study reported the use of CD34+ cells intending to take advantage of its vasculogenic and osteogenic potentials. CD34+ cells were harvested and transplanted after Granulocyte Colony Stimulating Factor (G-CSF) mobilization intravenously in a rat model to manage avascular necrosis. The study showed improved and promising results (Terayama et al., 2011). It has equally been reported that Mesenchymal Stem Cell (MSC) proliferation is affected during osteonecrosis (Wang et al., 2008). Thus, scientists have made several attempts to treat the disease condition by using MSC either by systemic intravenous administration or locally in the form of transplants/grafts in various animal models. Bone growth and regeneration have been linked to a myriad of cellular events involving growth factors and mediators such as the BMP, angiogenic growth factors, interleukins, and cytokines (Baltzer et al., 2000; Southwood et al., 2004; Roedersheimer et al., 2005; Uwagie-Ero et al., 2017). It is thought that with the application of these growth factors and cellular agents alone and in their combination, coupled with a well-defined surgical technique, healing of avascular necrosis of the femoral head lesions can be enhanced (Houdek et al., 2015; Ma et al., 2015). Animal studies have also investigated the use of BMP for the treatment and management of osteonecrosis (Houdek et al., 2015). The local administration of BMPs has been fraught with complications related to the high concentration needed to induce bone regeneration with resultant heterotopic bone formation (Govender et al., 2002; Vandermeer et al., 2011; Houdek et al., 2015; Ma et al., 2015). In addition to using BMP alone, BMPs has been used in 
combination with surgical modalities such as core decompression (Pan et al., 2014; Sun et al., 2014; Houdek et al., 2015;) and "trapdoor" bone grafting (Gibson, 1990; Mont et al., 2001) Osteonecrosis of the femoral head is a complex, multifactorial medical condition (Petek et al., 2019; Atilla et al., 2020) and the exact pathophysiology behind osteonecrosis is yet to be elucidated (Cardoso et al., 2019; Atilla et al., 2020). Currently, the use of ancillary growth factors for the treatment of this disease process attempts to treat osteonecrosis at a pathophysiological level (Atilla, 2020; Cardoso et al., 2018). Although promising reports have been observed in several animal models, the clinical use of adjuvant growth factors remains under investigation. (Cardoso et al., 2018; Atilla et al., 2020).

To date, conservative and surgical treatments are being used in the treatment of avascular necrosis (Demko \& McLaughin, 2005; Lika et al., 2012; Towle \& Breuer, 2012; DeCamp et al., 2016; Cardoso et al., 2018). The conservative treatment includes rest, controlled exercise, analgesic and anti-inflammatory medication, external coaptation, and physiotherapy (Nebzydoski, 1982; Gambardella, 1993; Lika et al., 2012). Chondroprotective medication and acupuncture; has also been reported to provide excellent outcomes. However, there are reports that only $25 \%$ of dogs recover from lameness after the conservative treatment (Gambardella, 2003; Demko \& McLaughin, 2005; Kim, 2011). Thus, reports suggest that surgical intervention should be ideal if there is no improvement of clinical signs after four weeks of conservative management (Millis, 2014).

A femoral head and neck osteotomy is the surgical procedure of choice in avascular necrosis of the femoral head. The procedure not only provides pain relief for the dog but also reduces lameness resulting from the condition (Nebzydoski, 1982; Gambardella, 1993; Lika et al., 2012; DeCamp et al., 2016; Harper, 2017). Dogs have been reported to experience mild intermittent lameness after the procedures. The outcome, however, has thus far been reported to be excellent (Millis, 2014; Cardoso et al., 2018). A major challenge to the management of avascular necrosis of the femoral head is the cost of surgery; most pet owners may not be able to afford the cost of initial surgery and may choose the option of euthanasia. Availability of suitable prosthetic devices is also a major challenge as they have to be ordered when needed, especially when all conservative management fails. This may account for the lack of follow-up of cases seen in this study. A major limitation to this study, however, was the challenge of poor record-keeping in a majority of the clinics assessed. The results obtained and reported in this study are therefore based on available records, this must be borne in mind in the interpretation and extrapolation of the results presented herein and should form part of policy recommendations in the management of and preservation of clinical data and records. Standardization of veterinary clinical data should be considered a priority.

The study showed a high prevalence of avascular necrosis of the femoral head in large breeds of dogs in Delta state. At the time of this study, management of the disease in the state is still largely conservative and follow up is relatively poor. Most pet owners see the condition as recalcitrant, and that may account for why they do not want to do a follow-up. Also, the cost of surgery and management may discourage owners from follow-up. However, surgery remains the gold standard for managing avascular necrosis of the femoral head in dogs.

\section{Conflict of Interest}

The authors declare that there is no conflict of interest.

\section{References}

Atilla B, Bakırcıoğlu S, Shope AJ, Parvızı J (2020). Jointpreserving procedures for osteonecrosis of the femoral head. EFORT Open Review, 28(4): 647-658.

Baltzer AW, Lattermann C, Whalen JD, Wooley P, Weiss P, Grimm M, Ghivizzani SC, Robbins PD, Evans CH (2000). Genetic enhancement of fracture repair: Healing of an experimental segmental defect by adenoviral transfer of the BMP-2 gene. Gene Therapy, 7(9): 734-9.

Bowlus RA, Armbrust LJ, Biller DS, Hoskinson JJ, Kuroki K \& Mosier DA (2008). Magnetic resonance imaging of the femoral head of normal dogs and dogs with avascular necrosis. Veterinary Radiology \& Ultrasound, 49(1): 7-12.

Cardoso CB, Rahal SC, Mamprim MJ, Oliveira HS, Melchert A, Coris JGF \& Mesquita LDR (2018). Avascular necrosis of the femoral head in dogs - Retrospective study. Acta Scientiae Veterinariae, 46(1): 1537.

David Y, Dominique JG, Page F, David S, Timothy MF \& Iwona MJ (2012). Bone resorption markers and dual-energy X-Ray absorptiometry in dogs with avascular necrosis, degenerative joint disease, and trauma of the coxofemoral joint. Veterinary Surgery, 41(5): 551-558.

DeCamp CE, Johnston SA, Déjardin LM \& Schaefer SL (2016). The hip joint. In: Brinker, Piermattei, and Flo's Handbook of Small Animal Orthopedics and Fracture Repair (DL 
Piermattei, editor). Fifth edition. St. Louis: Elsevier. Pp 468- 517.

Demko J \& McLaughlin R (2005). Developmental orthopedic disease. Veterinary Clinics of North America: Small Animal Practice, 35(5): 1111-1135.

Gambardella PC (1993). Legg-Calvé-Perthes disease in dogs. In: Disease Echanisms in Small Animal Surgery. Philadelphia (MJ Bojrab, DD Smeak, MS Bloomberg, editors): Lea \& Febiger. Pp 804-807.

George AH (1992). Radiographic Development of Canine Hip Dysplasia. Veterinary Clinics of North America: Small Animal Practice, 22(3): 559-578.

Gibson KL, Lewis DD \& Pechman RD (1990). Use of external coaptation for the treatment of avascular necrosis of the femoral head in a dog. Journal of American Veterinary Medical Association, 197(7): 868-870.

Ginja MM, Silvestre AM, Gonzalo-Orden JM \& Ferreira AJ (2010). Diagnosis, genetic control and preventive management of canine hip dysplasia: a review. Veterinary Journal, 184(3): 269-276.

Govender S, Csimma C, Genant HK, Valentin-Opran A, Amit $Y$, Arbel R, Aro $H$, Atar D, Bishay $M$, Börner MG, Chiron P, Choong $P$, Cinats J, Courtenay B, Feibel R, Geulette B, Gravel C, Haas N, Raschke M, Hammacher E, van der Velde D, Hardy P, Holt M, Josten C, Ketterl $\mathrm{RL}$, Lindeque $\mathrm{B}$, Lob $\mathrm{G}$, Mathevon $\mathrm{H}$, McCoy G, Marsh D, Miller R, Munting E, Oevre S, Nordsletten L, Patel A, Pohl A, Rennie W, Reynders $P$, Rommens $P M$, Rondia J, Rossouw WC, Daneel PJ, Ruff S, Rüter A, Santavirta S, Schildhauer TA, Gekle C, Schnettler R, Segal D, Seiler H, Snowdowne RB, Stapert J, Taglang G, Verdonk R, Vogels L, Weckbach A, Wentzensen A \& Wisniewski T (2002). Recombinant human bone morphogenetic protein-2 for treatment of open tibial fractures: A prospective, controlled, randomized study of four hundred and fifty patients. Journal of Bone and Joint Surgery, 84(12): 2123-2134.

Harper TAM (2017). Femoral Head and Neck Excision. Veterinary Clinics of North America Small Animal Practice, 47(4): 885-897.

Houdek MT, Wyles CC \& Sierra RJ (2015). Osteonecrosis of the femoral head: treatment with ancillary growth factors. Current Reviews in Musculoskeletal Medicine, 8(3): 233-239.
Isola M, Zotti A, Carnier P, Baroni E. \& Busetto R (2005). Dual-energy x-ray absorptiometry in canine Legg-Calvé-Perthes disease. Journal of Veterinary Medicine, 52(8): 407-410.

Jones DGC (1985). Conditions of the canine hip joint. The British Veterinary Journal, 141(6): 554563.

Kim HK (2011). Legg-Calve-Perthes disease: etiology, pathogenesis, and biology. Journal of Pediatric Orthopaedics, 31(2): S141-6

Kobayashi, R, Kurotaki T, Yamada N, Kumabe S, Doi T, Wako Y \& Tsuchitani, M (2015). Spontaneous and bilateral necrosis of the femoral head in a young experimental beagle dog. Journal of Toxicologic Pathology, 28(2): 121-124.

Levin D, Norman D, Zinman C, Rubinstein L, Sabo E, Misselevich I, Reis D \& Boss JH (1999). Treatment of experimental avascular necrosis of the femoral head with hyperbaric oxygen in rats: Histological evaluation of the femoral heads during the early phase of the reparative process. Experimental and Molecular Pathology, 67(2): 99-108.

Lika E, Gjino P, Belegu M, Duro S, Dimco E, Sherko E \& Turmalaj $L$ (2012). Retrospective study of the treatment of aseptic necrosis of the femoral head in dogs. Journal of Animal and Veterinary Advances, 11(16): 2930-2933.

Ma XW, Cui DP \& Zhao DW (2015). Vascular endothelial growth factor/bone morphogenetic protein-2 bone marrow combined modification of the mesenchymal stem cells to repair the avascular necrosis of the femoral head. International Journal of Clinical and Experimental Medicine, 8(9): 15528-15534.

Madore E, Huneault L, Moreau M \& Dupuis J (2007). Comparison of trot kinetics between dogs with stifle or hip arthrosis. Veterinary and Comparative Orthopaedics and Traumatology, 20(2): 102-107.

Millis DL (2014). Responses of musculoskeletal tissues to disuse and remobilization. Canine Rehabilitation and Physical Therapy, 7(1): 92-153.

Miyazaki M, Sugiyama O, Tow B, Zou J, Morishita Y, Wei F, Napoli A, Sintuu C, Lieberman JR \& Wang JC (2008). The effects of lentiviral gene therapy with bone morphogenetic protein2-producing bone marrow cells on spinal fusion in rats. Journal of Spinal Disorders Techniques, 21(5): 372-379.

Mont MA, Jones LC, Elias JJ, Inoue N, Yoon TR, Chao EY \& Hungerford DS (2001). Strutautografting with and without osteogenic 
protein-1: A preliminary study of a canine femoral head defect model. Journal of Bone and Joint Surgery, 83(7): 1013-1022.

Nebzydoski JA (1982). Ischemic necrosis of the femoral head in dogs: A review. Veterinary Medicine and Small Animal Clinician, 77(4): 631-636.

Pan ZX, Zhang HX, Wang YX, Zhai LD \& Du W (2014). Effect of recombinant human bone morphogenetic protein 2/poly-lactide-coglycolic acid (rhBMP-2/PLGA) with core decompression on repair of rabbit femoral head necrosis. Asian Pacific Journal of Tropical Medicine, 7(11): 895-899.

Peled E, Bejar J, Zinman C, Boss JH, Reis DN \& Norman $D$ (2009). Prevention of distortion of vascular deprivation-induced osteonecrosis of the rat femoral head by treatment with alendronate. Archives of Orthopedics and Trauma Surgery, 129: 275-279.

Petek D, Hannouche D \& Suva D (2019). Osteonecrosis of the femoral head: Pathophysiology and current concepts of treatment. EFORT Open Reviews, 4(3): 8597.

Robinson R (1992). Legg-Calvé-Perthes disease in dogs: Genetic aetiology. Journal of Small Animal Practice, 33(6): 275-276.

Roedersheimer M, West J, Huffer W, Harral J \& Benedict J (2005). A bone-derived mixture of TGF beta-superfamily members forms a more mature vascular network than bFGF or TGF-beta 2 in vivo. Angiogenesis, 8(4): 32738.

Southwood LL, Frisbie DD, Kawcak CE, Ghivizzani SC, Evans CH \& Mcllwraith CW (2004), Evaluation of Ad-BMP-2 for enhancing fracture healing in an infected defect fracture rabbit model. Journal of Orthopaedic Research, 22(1): 66-72.

Sun W, Li Z, Gao F, Shi Z, Zhang Q \& Guo W (2014). Recombinant human bone morphogenetic protein-2 in debridement and impacted bone graft for the treatment of femoral head osteonecrosis.

PLOSONE, doi.10.1371/journal.pone.0100424.

Terayama $\mathrm{H}$, Ishikawa $\mathrm{M}$, Yasunaga $\mathrm{Y}$, Yamasaki T, Hamaki T, Asahara T \& Ochi M (2011). Prevention of osteonecrosis by intravenous administration of human peripheral blood derived CD34-positive cells in a rat osteonecrosis model. Journal of Tissue Engineering and Regenerative Medicine, 5(1): 32-40.

Towle HA \& Breuer GJ (2012). Miscellaneous orthopedic conditions. In: Veterinary Surgery Small Animal (KM Tobias, SA Johnston editors). St. Louis: Elsevier Saunders. Pp 1112-1126.

Uwagie-Ero EA, Kene ROC \& Chilaka FC (2017). Bone Morphonetic proteins an update and review. Tropical Journal of Natural Products Research, 1(1): 1-11.

Vadasz Z, Misselevich I, Norman D, Peled E \& Boss JH (2004). Localization of vascular endothelial growth factor during the early reparative phase of the rats' vessels deprivation induced osteonecrosis of the femoral heads. Experimental and Molecular Pathology, 77(3): 145-148.

Vandermeer JS, Kamiya N, Aya-ay J, Garces A, Browne R \& Kim HK (2011). Local administration of ibandronate and bone morphogenetic protein-2 after ischemic osteonecrosis of the immature femoral head: A combined therapy that stimulates bone formation and decreases femoral head deformity. Journal of Bone and Joint Surgery, 93(10): 905-913.

Wang BL, Sun W, Shi ZC, Lou JN, Zhang NF, Shi SH, Guo WS, Cheng LM, Ye LY, Zhang WJ \& Li ZR (2008). Decreased proliferation of mesenchymal stem cells in corticosteroidinduced osteonecrosis of femoral head. Orthopedics, 31(5): $444-445$. 